\title{
Management of anticoagulants in delayed bleeding after endoscopic resection: A systematic review and meta-analysis
}

\section{다 (1) $(2)$}

\author{
Authors \\ Institutions \\ 1 Department of Gastroenterology, The Second Affiliated \\ Hospital of Guangzhou University of Chinese Medicine, \\ Guangdong, China \\ 2 The Second Clinical College of Guangzhou University of \\ Chinese Medicine, Guangdong, China \\ 3 Centre for Translational Medicine, The Second Affiliated \\ Hospital of Guangzhou University of Chinese Medicine, \\ Guangdong, China
}

Xianhong Zhao' ${ }^{1}$, Yangxue Huang ${ }^{2}$, Jiarong Li ${ }^{1}$, Aoqiang Zhou ${ }^{3}$, Gengxin Chen $^{3}$, Haixia Deng ${ }^{1}$

submitted 21.10 .2020

accepted after revision 2.3.2021

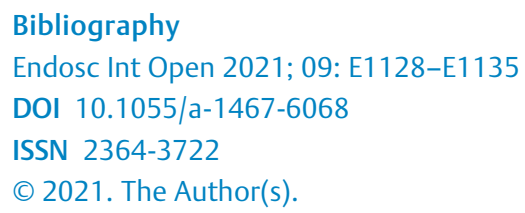

\section{ABSTRACT}

Background and study aims Delayed bleeding and thrombotic events are uncontrolled adverse events that are hard to balance in patients receiving anticoagulants after endoscopic resection. The present study aims to assess the clinical effect of warfarin, when compared to direct oral anticoagulants (DOACs), in terms of delayed bleeding and thrombotic events.

Methods A comprehensive electronic literature search was conducted for eligible literature. Pairwise meta-analyses were performed on outcomes of delayed bleeding and thrombotic events. Two networks within the Bayesian framework were established based on the management of anticoagulants and type of DOAC.

Results Eight cohort studies with 2,046 patients were eligible for inclusion, including 1,176 patients treated with warfarin and 870 with DOACs. There was no significant difference between warfarin and DOACs, in terms of delayed bleeding $(\mathrm{OR}=1.29,95 \% \mathrm{Cl}[0.99-1.69])$ and thromboembolism $(\mathrm{OR}=2.0,95 \% \mathrm{Cl}[0.32-12.39])$. In the network meta-analyses for delayed bleeding, the rank probabilities revealed that the safest management was discontinuous warfarin without heparin bridge therapy (HBT). Rank probabilities for the types of DOACs demonstrated that the safest drug was dabigatran.

Conclusions There was no significant difference in delayed bleeding and thromboembolism between warfarin and DOACs in patients receiving endoscopic treatment. In terms of delayed bleeding, discontinuous warfarin without HBT was suggested as the best management, and dabigatran was recommended as the best type of DOAC.

\section{Introduction}

Endoscopic resection is a minimally invasive treatment for gastrointestinal neoplasms that has been performed worldwide. However, post-procedural delayed bleeding remains as an uncontrolled adverse event (AE) that can lead to mortality and substantial costs to the health care system [1,2].
In an aging society, the number of patients taking anticoagulants has risen due to the increase in cardiovascular and cerebrovascular diseases [3]. Management of anticoagulant agents, including warfarin and direct oral anticoagulants (DOACs), remains controversial due to the difficulties in balan- 
cing the risk of gastrointestinal bleeding and thromboembolism [4].

It has been demonstrated that DOACs increased the incidence of gastrointestinal bleeding, when compared to warfarin, in patients without endoscopic treatment [5]. However, endoscopic procedural-related delayed bleeding has not been completely elucidated. Therefore, the investigators conducted the present meta-analysis to evaluate the clinical effect of warfarin, when compared to DOACs, in terms of delayed bleeding and thrombotic events in patients receiving endoscopic treatment.

\section{Methods}

\section{Search strategy}

The present meta-analysis was reported according to the Preferred Reporting Items for Systematic Reviews and Meta-Analyses (PRISMA) [6].

A comprehensive electronic literature search was performed to identify all comparative studies published in PubMed, Embase, the Cochrane Library, and Web of Science, from inception to August 31, 2020. The following MeSH terms were used in combination: “Endoscopic Resection”, “Anticoagulants”, “Warfarin", and "Bleeding". The reference lists of the included studies were also reviewed as a supplement. No language limits were applied.

\section{Inclusion and exclusion criteria}

The inclusion criteria were, as follows: (1) studies conducted on patients who received endoscopic treatment for gastrointestinal neoplasms; (2) comparative studies that evaluated the incidence of delayed bleeding and thrombotic events between warfarin and DOACs; (3) because no randomized controlled trial (RCT) has been published, the study design was limited to observational cohort studies.

The exclusion criteria were, as follows: (1) studies conducted on patients who received endoscopic treatment for biliary tract diseases; (2) the novel endoscopic technique or material has not been widely used; and (3) studies that used excessive missing data to evaluate the comparability and reliability.

Study selection

Two authors independently reviewed the titles and abstracts, and excluded the studies that did not meet the inclusion criteria pre-specified before the screening. The full text of the remaining articles was reviewed to determine whether this provided the related information used to address the research question. Any discrepancy was resolved by discussion or consensus with a co-author.

\section{Data extraction}

The data were independently extracted by two authors from each eligible study. The extracted data included the first author's last name, publication year, study design, participant characteristics (age and gender), management of anticoagulants including continuation, discontinuation without heparin bridge therapy (HBT) and discontinuation with $\mathrm{HBT}$, the use of antiplatelets, lesion site, and guidelines.
Based on the guidelines published in 2014 by the Japan Gastroenterological Endoscopy Society (JGES) [7], warfarin was stopped at 3 to 5 days before endoscopy and DOACs were stopped after 1 to 2 days. For those treated with HBT, as determined by the prescribing physician and endoscopists, this was started with the cessation of warfarin and DOACs, and subsequently stopped at 4 to 6 hours before endoscopic treatment. Heparin and warfarin were restarted when no bleeding was confirmed at the day after endoscopic treatment. Heparin was discontinued after the prothrombin time-international normalized ratio (PT-INR) achieve the therapeutic level. The DOACs were resumed at postoperative day one, but without heparin.

The primary outcomes were the incidence of delayed bleeding and thrombotic events. Delayed bleeding was defined as hematemesis, melena, or a decrease of over $2 \mathrm{~g} / \mathrm{dL}$ of hemoglobin after endoscopic resection. A thrombotic event was defined as the occurrence of ischemic heart diseases, stroke, transient ischemic attack, pulmonary embolism, deep vein thrombosis, or arterial thrombosis.

Quality assessment

The observational cohort studies were assessed using Newcastle-Ottawa scale (NOS) [8], which was categorized into three groups: the selection of the study group and control group (4 points), the comparability of the two groups (2 points), and the identification of outcomes (3 points). A score within 0-9 was allocated to each study. The outcome assessment of 7 points or more implied a high quality.

Statistical analysis

First, to compare the outcomes of delayed bleeding and thrombotic events between warfarin and DOACs, we used the random effects model and all the analyses were conducted pair-wise. The results were expressed as odds ratios (ORs) with $95 \%$ confidence intervals ( $95 \% \mathrm{Cls})$. The inconsistency statistic $\left(I^{2}\right)$ was used for the assessment of heterogeneity. Publication bias was illustrated with the funnel plot and assessed using the visual inspection, and quantitatively determined by Egger's test. All analyses were carried out using the STATA/SE software version 12.0 (StataCorp LP, College Station, Texas, United States).

Second, the network meta-analyses that calculated the direct and indirect estimates of delayed bleeding based on the management of anticoagulants and types of DOACs were performed using the random-effects model within the Bayesian framework in ADDIS version 1.16.6 (IMI GetReal Initiative, EU). The results were reported as ORs with the corresponding 95\% Cls. Significant inconsistency was indicated when one of the following three conditions was met: (1) the $95 \% \mathrm{Cl}$ for an inconsistency factor did not contain 0; (2) the difference between random effects variance and inconsistency variance was large; (3) the random effects variance significantly decreased from the consistency model to the inconsistency model [9]. The consistency model was used to draw the conclusions, when no relevant inconsistency was detected. In addition, each treatment was ranked by calculating the accumulated OR, based on the Markov chain Monte Carlo method [10]. 


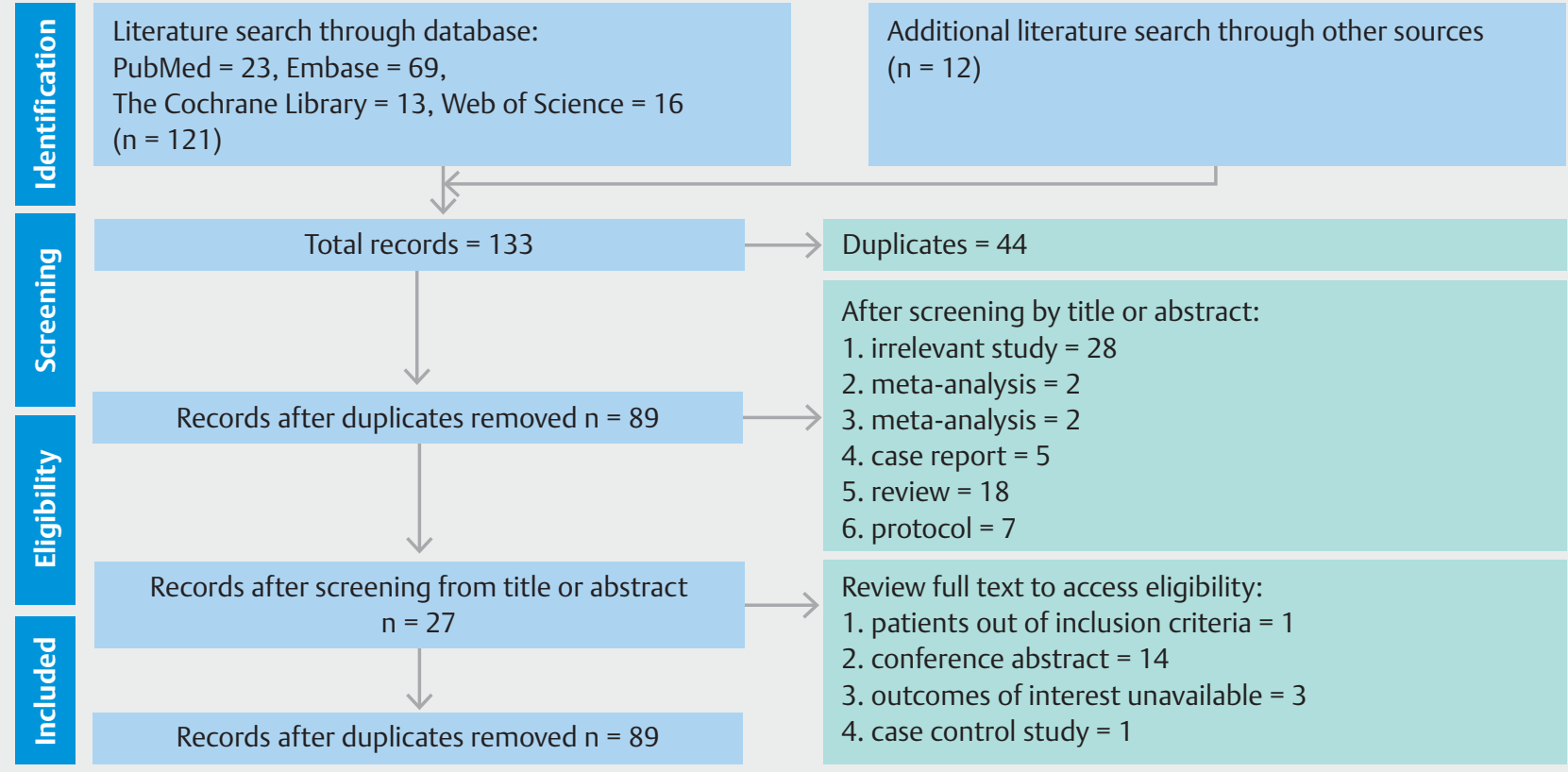

Fig. 1 Flow diagram of the included studies.

\section{Results}

\section{Study selection}

The electronic search identified 121 articles, and 12 additional studies were identified through the manual search of reference lists. A total of 89 papers were evaluated after duplicates removed. After screening through the titles or abstracts, 28 studies were removed as irrelevant studies. Furthermore, 34 articles were excluded due to the study design. After reviewing the fulltext of the remaining 27 articles, a total of 19 studies were found to be ineligible for the inclusion criteria, and were excluded. Finally, eight studies [11-18] were included for the meta-analysis. Results of the study flow diagram are shown in

-Fig. 1.

\section{Basic characteristics and quality of the included studies}

The included studies were published between 2017 and 2020 . A total of 2,046 patients were enrolled in the present meta-analysis, which included 1,176 patients treated with warfarin and 870 patients with DOACs. All included studies reported the incidence of delayed bleeding and thrombotic events. According to the NOS, the included studies acquired scores that ranged within 7-8. The characteristics of the included studies are described in $>$ Table 1. Quality assessment is described in detail in Supplementary Table 1.

\section{Pairwise meta-analysis}

Delayed bleeding

All articles reported this outcome, with a total of 2,046 patients ( 1,176 patients with warfarin and 870 patients with DOACs). There was no significant difference between the warfarin and DOACs groups (OR $=1.29,95 \% \mathrm{Cl}$ [0.99-1.69]), and there was no heterogeneity $\left(I^{2}=0, P=0.787\right)$. The subgroup analysis revealed a similar result between gastric and colorectal endoscopic procedurals. The pooled ORs were 1.34 (95\% Cl [0.901.98]) and 0.85 (95\% Cl [0.45-1.61]), respectively (> Fig. 2). A funnel plot is shown in Supplementary Fig. 1. No publication bias was detected based on the Egger's test $(P=0.132)$.

\section{Thrombotic events}

All articles demonstrated the outcome, and five of these [1115] reported no thrombotic events. Therefore, the meta-analysis was conducted using three studies [16-18] with a total of 1,085 patients (601 patients with warfarin and 484 patients with DOACs). No significant difference was found between the warfarin and DOACs groups (OR=2.0, 95\% Cl [0.32-12.39]), and there was no heterogeneity $\left(I^{2}=0, P=0.879\right)$ ( $\triangleright$ Fig. 3). Funnel plot was illustrated in Supplementary Fig. 2. No publication bias was detected based on the Egger's test $(P=0.681)$.

\section{Networks}

Networks on the management of anticoagulants

A total of five articles $[11-13,17,18]$ were included in the network. Based on the management of anticoagulants, six different groups assigned. The discontinuation of warfarin and 
Table 1 Characteristics of the included studies.

\begin{tabular}{|c|c|c|c|c|c|c|c|c|c|c|c|c|}
\hline \multirow[t]{2}{*}{ Study } & \multirow[t]{2}{*}{ Year } & \multirow{2}{*}{$\begin{array}{l}\text { De- } \\
\text { sign }\end{array}$} & \multirow[t]{2}{*}{ Groups } & \multirow{2}{*}{$\begin{array}{l}\text { Pa- } \\
\text { tients }\end{array}$} & \multirow{2}{*}{$\begin{array}{l}\text { Age, } \\
\text { mean } \pm S D\end{array}$} & \multirow{2}{*}{$\begin{array}{l}\text { Male, } \\
\%\end{array}$} & \multicolumn{3}{|c|}{ Treatment Strategy } & \multirow{2}{*}{$\begin{array}{l}\text { Use of } \\
\text { anti- } \\
\text { plate- } \\
\text { lets, \% }\end{array}$} & \multirow{2}{*}{$\begin{array}{l}\text { Lesion } \\
\text { site }\end{array}$} & \multirow{2}{*}{$\begin{array}{l}\text { Guide- } \\
\text { lines }\end{array}$} \\
\hline & & & & & & & $\begin{array}{l}\text { Conti- } \\
\text { nua- } \\
\text { tion, } \\
\%\end{array}$ & $\begin{array}{l}\text { Cessa- } \\
\text { tion, } \\
\%\end{array}$ & $\begin{array}{l}\text { HBT, } \\
\%\end{array}$ & & & \\
\hline \multirow{2}{*}{$\begin{array}{l}\text { Tomi- } \\
\text { da } \\
{[10]}\end{array}$} & \multirow[t]{2}{*}{2020} & \multirow{2}{*}{$\begin{array}{l}\text { Retro- } \\
\text { spec- } \\
\text { tive } \\
\text { cohort }\end{array}$} & $\begin{array}{l}\text { Warfar- } \\
\text { in }\end{array}$ & 467 & $76.0 \pm 4.0$ & $84.4 \%$ & $4.5 \%$ & $35.5 \%$ & $60.0 \%$ & $26.1 \%$ & \multirow[t]{2}{*}{$\begin{array}{l}\text { Stom- } \\
\text { ach }\end{array}$} & \multirow[t]{2}{*}{ JGES } \\
\hline & & & DOACs & 261 & $74.0 \pm 5.2$ & $89.7 \%$ & $5.4 \%$ & $78.9 \%$ & $15.7 \%$ & $17.0 \%$ & & \\
\hline \multirow{2}{*}{$\begin{array}{l}\text { Hara- } \\
\text { da } \\
{[11]}\end{array}$} & \multirow[t]{2}{*}{2020} & \multirow{2}{*}{$\begin{array}{l}\text { Retro- } \\
\text { spec- } \\
\text { tive } \\
\text { cohort }\end{array}$} & $\begin{array}{l}\text { Warfar- } \\
\text { in }\end{array}$ & 26 & $74.8 \pm 9.1$ & $69.2 \%$ & $53.8 \%$ & $23.1 \%$ & $23.1 \%$ & $38.5 \%$ & \multirow[t]{2}{*}{ Colon } & \multirow{2}{*}{$\begin{array}{l}\text { JGES } \\
\text { and } \\
\text { ASGE }\end{array}$} \\
\hline & & & DOACs & 25 & $77.1 \pm 6.4$ & $60.0 \%$ & 0 & $84 \%$ & $16.0 \%$ & $40.0 \%$ & & \\
\hline \multirow{2}{*}{$\begin{array}{l}\text { Hama- } \\
\text { da } \\
{[12]}\end{array}$} & \multirow[t]{2}{*}{2020} & \multirow{2}{*}{$\begin{array}{l}\text { Retro- } \\
\text { spec- } \\
\text { tive } \\
\text { cohort }\end{array}$} & $\begin{array}{l}\text { Warfar- } \\
\text { in }\end{array}$ & 24 & $79.0 \pm 6.5$ & $88.0 \%$ & 0 & 0 & $100 \%$ & $29 \%$ & \multirow[t]{2}{*}{$\begin{array}{l}\text { Stom- } \\
\text { ach }\end{array}$} & \multirow[t]{2}{*}{ JGES } \\
\hline & & & DOACs & 8 & $73.3 \pm 5.2$ & $88.0 \%$ & 0 & 0 & $100 \%$ & $38 \%$ & & \\
\hline \multirow{2}{*}{$\begin{array}{l}\text { Yasu- } \\
\text { da } \\
{[13]}\end{array}$} & \multirow[t]{2}{*}{2019} & \multirow{2}{*}{$\begin{array}{l}\text { Retro- } \\
\text { spec- } \\
\text { tive } \\
\text { cohort }\end{array}$} & $\begin{array}{l}\text { Warfar- } \\
\text { in }\end{array}$ & 34 & $73.2 \pm 6.7$ & $67.6 \%$ & 0 & 0 & $100 \%$ & $8.0 \%$ & \multirow[t]{2}{*}{ Colon } & \multirow[t]{2}{*}{ ASGE } \\
\hline & & & DOACs & 63 & $74.2 \pm 7.0$ & $66.7 \%$ & NA & NA & NA & $11.0 \%$ & & \\
\hline \multirow[t]{2}{*}{$\begin{array}{l}\text { Ono } \\
{[14]}\end{array}$} & \multirow[t]{2}{*}{2019} & \multirow{2}{*}{$\begin{array}{l}\text { Retro- } \\
\text { spec- } \\
\text { tive } \\
\text { cohort }\end{array}$} & $\begin{array}{l}\text { Warfar- } \\
\text { in }\end{array}$ & 24 & $\begin{array}{l}65.3 \pm \\
16.0\end{array}$ & $75.0 \%$ & $41.7 \%$ & 0 & $58.3 \%$ & $29.2 \%$ & Colon & JGES \\
\hline & & & DOACs & 27 & $69.6 \pm 7.1$ & $75.0 \%$ & 0 & $100 \%$ & 0 & $21.4 \%$ & & \\
\hline $\begin{array}{l}\text { Kubo } \\
{[15]}\end{array}$ & 2019 & $\begin{array}{l}\text { Retro- } \\
\text { spec- }\end{array}$ & $\begin{array}{l}\text { Warfar- } \\
\text { in }\end{array}$ & 383 & $73.3 \pm 8.4$ & $78.9 \%$ & NA & NA & $37.2 \%$ & $22.8 \%$ & $\begin{array}{l}\text { Gas- } \\
\text { troin- }\end{array}$ & JGES \\
\hline & & cohort & DOACs & 389 & $74.5 \pm 7.6$ & $75.1 \%$ & & & & & al & \\
\hline $\begin{array}{l}\text { Yana- } \\
\text { gisawa }\end{array}$ & 2018 & $\begin{array}{l}\text { Retro- } \\
\text { spec- }\end{array}$ & $\begin{array}{l}\text { Warfar- } \\
\text { in }\end{array}$ & 145 & NA & $71.0 \%$ & $29.7 \%$ & $13.1 \%$ & $57.2 \%$ & $30.0 \%$ & Colon & $\begin{array}{l}\text { JGES } \\
\text { and }\end{array}$ \\
\hline & & cohort & DOACs & 73 & NA & $74.0 \%$ & $68.5 \%$ & $5.5 \%$ & $26.0 \%$ & $13.7 \%$ & & \\
\hline $\begin{array}{l}\text { Yoshio } \\
{[17]}\end{array}$ & 2017 & $\begin{array}{l}\text { Retro- } \\
\text { spec- }\end{array}$ & $\begin{array}{l}\text { Warfar- } \\
\text { in }\end{array}$ & 73 & $76.0 \pm 5.2$ & $93.2 \%$ & 0 & $22.0 \%$ & $78.0 \%$ & $27.4 \%$ & $\begin{array}{l}\text { Stom- } \\
\text { ach }\end{array}$ & JGES \\
\hline & & cohort & DOACs & 24 & $74.0 \pm 5.5$ & $91.7 \%$ & 0 & $33.3 \%$ & $66.7 \%$ & $12.5 \%$ & & \\
\hline
\end{tabular}

DOACs, direct oral anticoagulants; HBT, heparin bridging therapy; JGES, Japan Gastroenterological Endoscopy Society; ASGE, American Society for Gastrointestinal Endoscopy; NA, data not acquired.

DOACs with HBT were the two most commonly investigated types ( $\mathbf{F i g} . \mathbf{4 c}$ ).

The pooled network OR values revealed that the continuation of DOACs $(\mathrm{OR}=6.91,95 \% \mathrm{Cl}$ [1.42-93.92]) and discontinuation of warfarin with $\mathrm{HBT}(\mathrm{OR}=5.53,95 \% \mathrm{Cl}$ [1.55-58.73]) had a significantly higher odds for delayed bleeding, when compared to the discontinuation of warfarin without HBT. There was no significant difference among the other types of management ( $\triangleright$ Fig.4b). The ranking indicated that the safest management was the discontinuation of warfarin without HBT (> Fig.4d).

In this network, the $95 \% \mathrm{Cl}$ of inconsistency factors all contained 0 . The random effects variance and inconsistency variance were 0.82 and 0.88 , respectively. The random effects var- iance of the consistency and inconsistency model were 0.88 and 0.82 , respectively.

\section{Networks on the types of DOACs}

A total of six articles $[11,12,15-18]$ were included in the network, based on the types of DOACs, and these were divided into four different drugs. Dabigatran and rivaroxaban were the two most commonly investigated drugs ( $>$ Fig. 5a).

The pooled network $O R$ values revealed that apixaban $(\mathrm{OR}=$ $3.02,95 \% \mathrm{Cl}$ [1.10-8.10]) had significantly higher odds for delayed bleeding, when compared to dabigatran. There was no significant difference among the other drugs ( $\triangleright$ Fig. 5b). The ranking indicated that the safest drug was dabigatran ( $>$ Fig. 5c).

In this network, the $95 \% \mathrm{Cl}$ of inconsistency factors all contained 0 . The random effects variance and inconsistency var- 


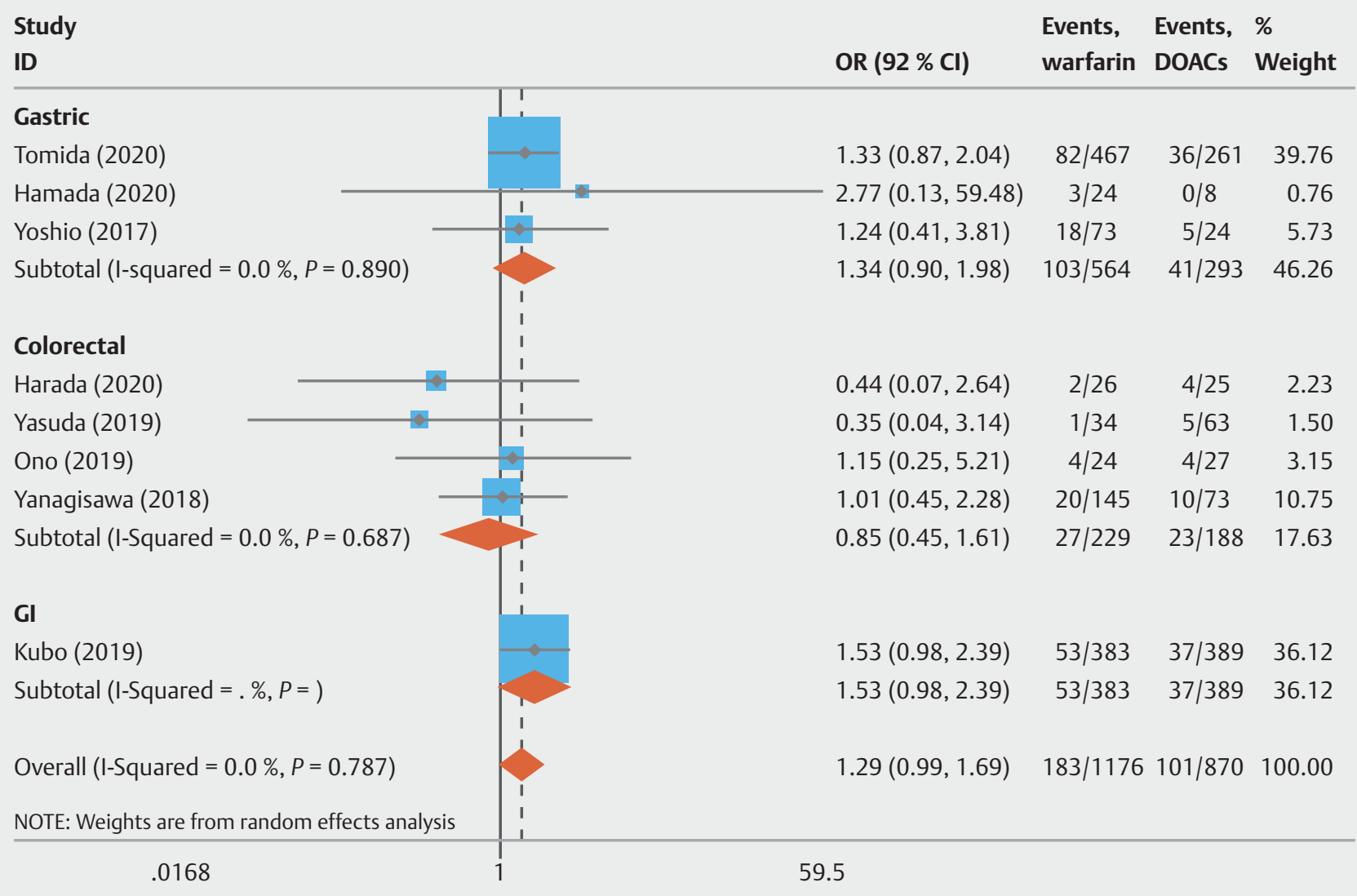

Fig. 2 Pairwise meta-analysis on delayed bleeding. Gl, gastrointestinal tract; DOACs, direct oral anticoagulants; OR, odds ratio; Cl, confidence interval.

\begin{tabular}{|c|c|c|c|c|c|}
\hline $\begin{array}{l}\text { Study } \\
\text { ID }\end{array}$ & & OR $(92 \% \mathrm{Cl})$ & $\begin{array}{l}\text { Events, } \\
\text { warfarin }\end{array}$ & $\begin{array}{l}\text { Events, } \\
\text { DOACs }\end{array}$ & $\begin{array}{l}\% \\
\text { Weight }\end{array}$ \\
\hline Kubo (2019) & - & $3.05(0,12,75.22)$ & $1 / 383$ & $0 / 389$ & 32.41 \\
\hline Yanagisawa (2018) & $\frac{1}{1}$ & $2.49(0.12,52.88)$ & $2 / 145$ & $0 / 71$ & 35.77 \\
\hline Yoshio (2017) & i & $1.01(0.04,25.71)$ & $1 / 73$ & $0 / 24$ & 31.82 \\
\hline Overall (I-Squared $=0.0 \%, P=0.879)$ & i & $2.00(0.32,12.39)$ & $4 / 601$ & $0 / 484$ & 100.00 \\
\hline NOTE: Weights are from random effects analysis & I & & & & \\
\hline
\end{tabular}

Fig. 3 Pairwise meta-analysis on thrombotic events. DOACs, direct oral anticoagulants; OR, odds ratio; Cl, confidence interval.

iance were 0.53 and 0.97 , respectively. The random effects variance of the consistency and inconsistency model were 0.45 and 0.53 , respectively.

\section{Discussion}

The present study was the first meta-analysis that compared warfarin to DOACs in patients receiving endoscopic treatment. We demonstrated that there was no significant difference between warfarin and DOACs, in terms of delayed bleeding and thrombotic events. The discontinuation of warfarin without 
Management of anticoagulant

\begin{tabular}{ll}
\hline Warfarin 1 & Continuous warfarin \\
Warfarin 2 & Discontinuous warfarin without HBT \\
Warfarin 3 & Discontinuous warfarin with HBT \\
DOACs 1 & Continuous DOACs \\
DOACs 2 & Discontinuous DOACs without HBT \\
DOACs 3 & Discontinuous DOACs with HBT
\end{tabular}

a

\section{DOACs 1}

$1.24(0.24,6.42)$

$1.88(0.34,10.74)$

$2.42(0.42,15.19)$

$3.45(0.58,22.64)$

$6.91(1.42,93.92)$

\section{Warfarin 3}

$1.53(0.41,5.77)$

$1.95(0.43,8.93)$

$2.76(0.66,12.87)$

$5.53(1.55,58.73)$

\section{DOACs 3}

$1.28(0.26,6.30)$

$1.83(0.41,8.74)$

$3.62(0.92,37.83)$
Warfarin 1

$1.41(0.29,7.57)$

$2.85(0.64,34.39)$
DOACs 2

$1.98(0.50,21.29) \quad$ Warfarin 2

Network ORs $(95 \% \mathrm{Cl})$

b

Decreasing odds for delayed bleeding

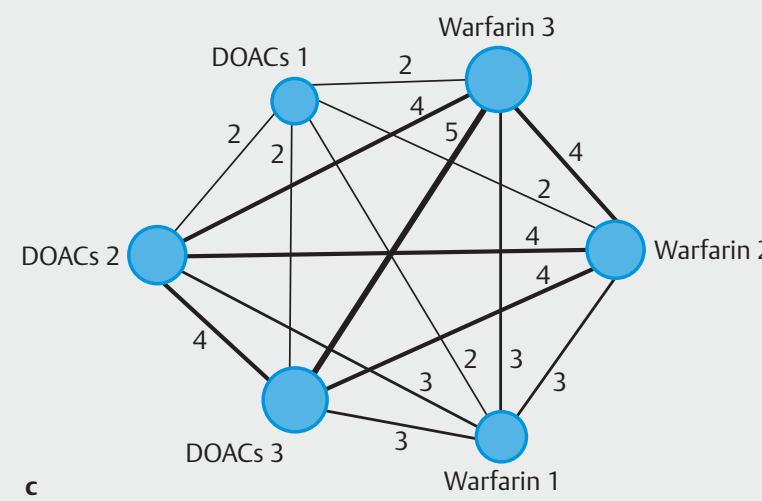

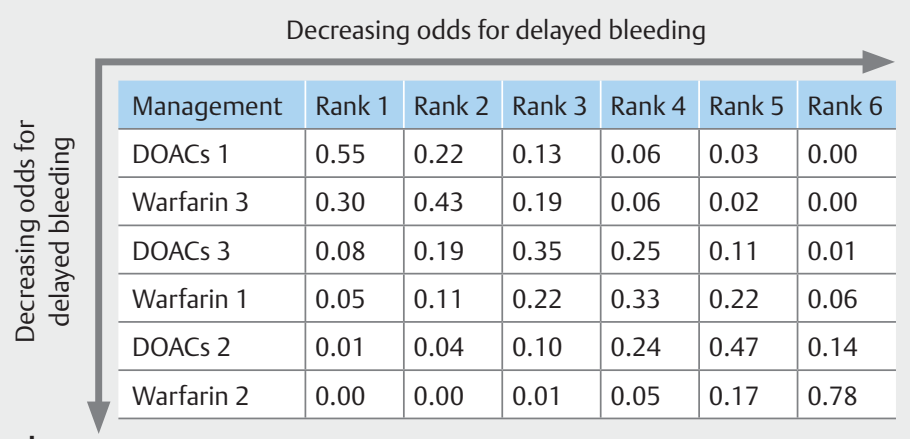

d

- Fig. 4 Network meta-analysis based on management of anticoagulants. a Descriptions of managements included in the network. b Outcomes of comparisons among different treatments regarding delayed bleeding. c Network plot established for multiple treatments comparisons. The size of each blue node represents the total number of patients. The width of each connecting line represents the number of trials between the two nodes. d Rank probabilities of each treatments. DOACs, direct oral anticoagulants; OR, odds ratio; Cl, confidence interval.

HBT was potentially the best treatment, while the continuation of DOACs and discontinuation of warfarin with HBT tended be the worst treatment with regard to delayed bleeding. In addition, dabigatran had the greatest probability of ranking as the safest among all four DOACs in terms of delayed bleeding.

Warfarin has different pharmacological properties from DOACs. It targets vitamin $\mathrm{K}$ epoxide reductase to block the function of coagulation factors II, III, IX, and X [11]. Several meta-analyses $[5,19,20]$ have demonstrated that DOACs increase the incidence of gastrointestinal bleeding, when compared to warfarin, in patients with atrial fibrillation. Furthermore, it has been reported that DOACs directly target coagulation proteins, and that these cannot be incompletely absorbed by the gastrointestinal tract, which have both systemic and local effects on the GI mucosa [18]. In contrast, some diversity of opinion revealed that DOACs are superior to warfarin, in terms of gastrointestinal bleeding [4,21]. A possible explanation is that warfarin with a slow onset/offset of anticoagulant effect may increase the risk of bleeding, while the onset/offset is rapid with DOACs [22,23]. Meanwhile, with warfarin use, the INR reaches the therapeutic level. Therefore, for discontinuous warfarin patients, heparin, which is considered as the risk factor of delayed bleeding [3], may need to be used for a longer period of time, when compared to DOACs, after the endoscopic procedure. In the present analysis, it was found that there was no statistically significant difference between warfarin and DOACs, in terms of delayed bleeding. It is noteworthy that the lower bound of $95 \% \mathrm{Cl}$ was 0.99 , which was quite close to 1 . It cannot be ignored that there is possibility that this may reach statistical significance once the sample size becomes larger. More multicenter RCTs are expected to verify these conclusions.

For warfarin patients, the discontinuation of warfarin without HBT was probably the best choice for delayed bleeding, based on the present analysis. It has been reported that warfarin therapy withheld for $\leq 5$ days is correlated to low risk of thromboembolism, with a probability of $0.7 \%$ [24]. However, attention should also be given to the management of the continuation of warfarin. The presented analysis revealed that there was no significant difference between the two managements, in terms of delayed bleeding. Therefore, for patients 


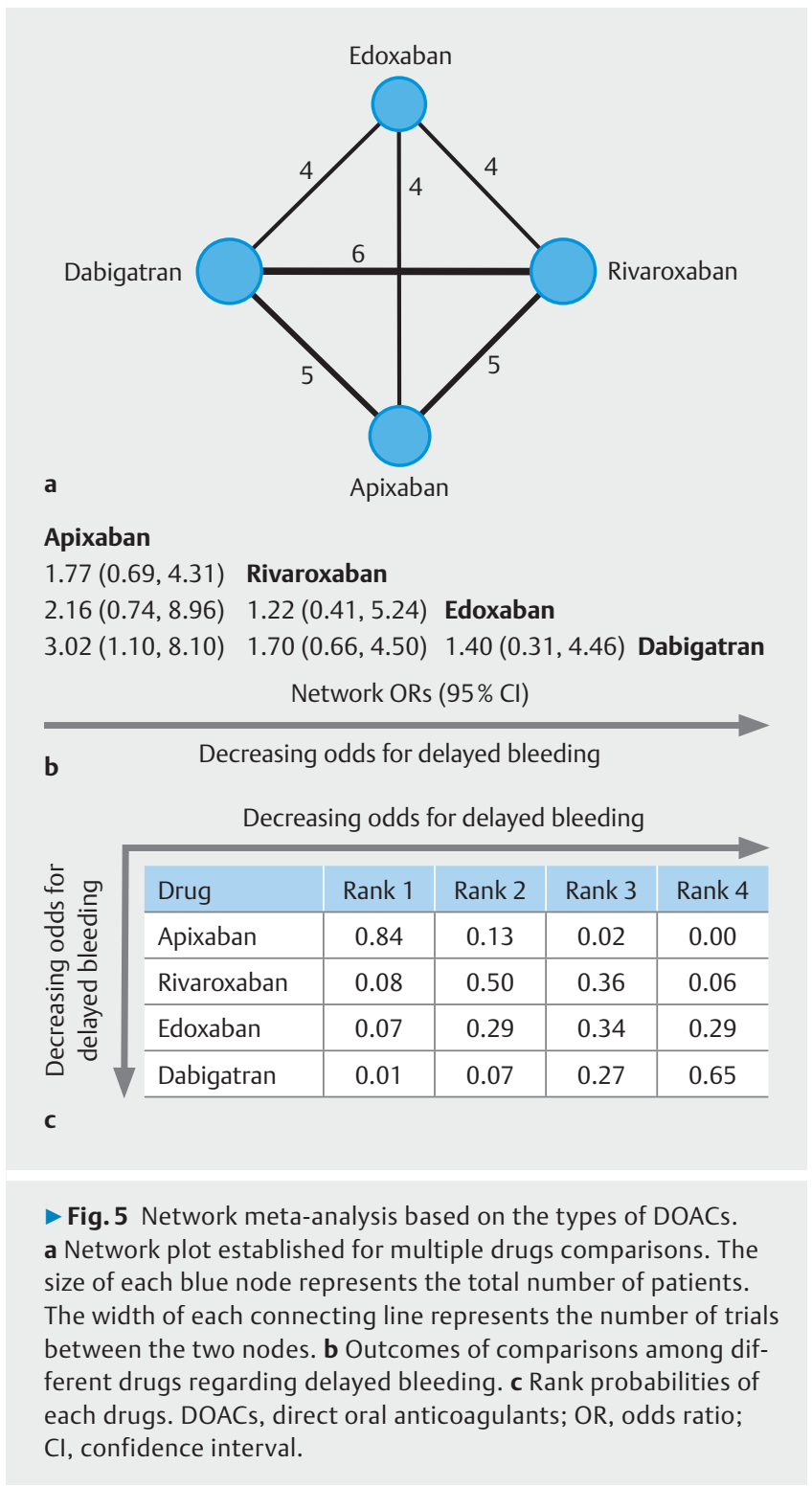

with high risk of thrombotic events, according to $\mathrm{CHADS}_{2}$ or other predictive models [25], the continuation of warfarin appears to be a good option.

The present study demonstrated that dabigatran had the greatest probability to rank the safest among the four DOACs, in terms of delayed bleeding. It should be stated that dabigatran, which is a thrombin inhibitor with no anticoagulant activity, can be converted to its active form by hepatic and serum esterases [26]. Different from other Xa inhibitors, dabigatran may not have an anticoagulant effect on post-procedural endoscopic ulcer.

There were several limitations of the present study. First, although management of anticoagulant was determined according to the same guidelines published by JGES, the management of warfarin and DOACs varied in several ways, as determined by the prescribing physician and endoscopists. Therefore, two networks were conducted, which can be considered as a subgroup analysis, to more comprehensively evaluate the occurrence of delayed bleeding. However, for thrombotic events, this could not be examined in detail in the present study due to the lower incidence rate. In addition, for the pairwise results of thromboembolism, the $\mathrm{Cl}$ was significantly broad that the results very strongly suggested a type II error. Multicenter RCTs with large sample size to evaluate the actual risk of delayed bleeding and thromboembolism are needed to draw a precise conclusion. Second, although the number of patients using antiplatelet agents was strictly controlled at baseline, between the warfarin and DOACs groups, the investigators could not evaluate the cases treated with more than two types of antiplatelets because the data was reported only by a few of the included trials. Third, outcomes may be confounded by the dose of drugs, primary diseases, and experience of the endoscopist, which was difficult to unify. Fourth, the included studies were retrospective in nature, which may lead to risk of selection bias.

\section{Conclusions}

In conclusion, the present study indicated that there was no significant difference between warfarin and DOACs in patients receiving endoscopic treatment, in terms of delayed bleeding and thromboembolism. Discontinuous warfarin without HBT was suggested to potentially be the best management, and dabigatran was recommended to potentially be the best drug for DOACs.

\section{Acknowledgements}

Funding for this work was provided by The Specific Research Fund for TCM Science and Technology of Guangdong Provincial Hospital of Chinese Medicine, China (No. YN2016ML06).

\section{Competing interests}

The authors declare that they have no conflict of interest.

\section{References}

[1] Okada K, Yamamoto Y, Kasuga A et al. Risk factors for delayed bleeding after endoscopic submucosal dissection for gastric neoplasm. Surg Endosc 2011; 25: 98-107

[2] Shaukat A, Mongin SJ, Geisser MS et al. Long-term mortality after screening for colorectal cancer. N Engl J Med 2013; 369: 1106-1114

[3] Sanomura Y, Oka S, Tanaka S et al. Taking warfarin with heparin replacement and direct oral anticoagulant is a risk factor for bleeding after endoscopic submucosal dissection for early gastric cancer. Digestion 2018; 97: 240-249

[4] Nagata N, Yasunaga H, Matsui $\mathrm{H}$ et al. Therapeutic endoscopy-related $\mathrm{Gl}$ bleeding and thromboembolic events in patients using warfarin or direct oral anticoagulants: results from a large nationwide database analysis. Gut 2018; 67: 1805-1812

[5] Ruff CT, Giugliano RP, Braunwald E et al. Comparison of the efficacy and safety of new oral anticoagulants with warfarin in patients with atrial fibrillation: a meta-analysis of randomised trials. Lancet 2014; 383: 955-962 
[6] Liberati A, Altman DG, Tetzlaff ] et al. The PRISMA statement for reporting systematic reviews and meta-analyses of studies that evaluate healthcare interventions: explanation and elaboration. BMJ 2009; 339: b2700

[7] Fujimoto K, Fujishiro M, Kato M et al. Guidelines for gastroenterological endoscopy in patients undergoing antithrombotic treatment. Dig Endosc 2014; 26: 1-14

[8] Stang A. Critical evaluation of the Newcastle-Ottawa scale for the assessment of the quality of nonrandomized studies in meta-analyses. Eur J Epidemiol 2010; 25: 603-605

[9] Liang W, Wu X, Fang W et al. Network meta-analysis of erlotinib, gefitinib, afatinib and icotinib in patients with advanced non-small-cell lung cancer harboring EGFR mutations. PLoS One 2014; 9: e85245

[10] Goring SM, Gustafson P, Liu Y et al. Disconnected by design: analytic approach in treatment networks having no common comparator. Res Synth Methods 2016; 7: 420-432

[11] Tomida H, Yoshio T, Igarashi K et al. Influence of anticoagulants on the risk of delayed bleeding after gastric endoscopic submucosal dissection: a multicenter retrospective study. Gastric Cancer 2021; 24: 179189

[12] Harada H, Nakahara R, Murakami D et al. The effect of anticoagulants on delayed bleeding after colorectal endoscopic submucosal dissection. Surg Endosc 2020; 34: 3330-3337

[13] Hamada K, Kanzaki H, Inoue M et al. Continued aspirin treatment may be a risk factor of delayed bleeding after gastric endoscopic submucosal dissection under heparin replacement: a retrospective multicenter study. Intern Med 2020; 59: 2643-2651

[14] Yasuda R, Yoshida N, Murakami T et al. Multicenter study of the hemorrhage risk after endoscopic mucosal resection associated with direct oral anticoagulants. Gastroenterol Res Pract 2019; 2019: 1-8

[15] Ono S, Ishikawa M, Matsuda K et al. Clinical impact of the perioperative management of oral anticoagulants in bleeding after colonic endoscopic mucosal resection. BMC Gastroenterol 2019; 19: 206

[16] Kubo K, Kato M, Mabe K et al. Risk Factors for Delayed Bleeding after Therapeutic Gastrointestinal Endoscopy in Patients Receiving Oral
Anticoagulants: A Multicenter Retrospective Study. Digestion 2019; 102: 1-9

[17] Yanagisawa N, Nagata N, Watanabe K et al. Post-polypectomy bleeding and thromboembolism risks associated with warfarin vs direct oral anticoagulants. World J Gastroenterol 2018; 24: 1540-1549

[18] Yoshio T, Tomida H, Iwasaki R et al. Effect of direct oral anticoagulants on the risk of delayed bleeding after gastric endoscopic submucosal dissection. Dig Endosc 2017; 29: 686-694

[19] Miller CS, Grandi SM, Shimony A et al. Meta-analysis of efficacy and safety of new oral anticoagulants (dabigatran, rivaroxaban, apixaban) versus warfarin in patients with atrial fibrillation. Am J Cardiol 2012; 110: $453-460$

[20] Jia B, Lynn HS, Rong F et al. Meta-analysis of efficacy and safety of the new anticoagulants versus warfarin in patients with atrial fibrillation. J Cardiovasc Pharmacol 2014; 64: 368-374

[21] Cangemi DJ, Krill T, Weideman R et al. A comparison of the rate of gastrointestinal bleeding in patients taking non-vitamin $\mathrm{K}$ antagonist oral anticoagulants or warfarin. Am J Gastroenterol 2017; 112: 734739

[22] Abraham NS, Castillo DL. Novel anticoagulants: bleeding risk and management strategies. Curr Opin Gastroenterol 2013; 29: 676-683

[23] Baron TH, Kamath PS, McBane RD. New anticoagulant and antiplatelet agents: a primer for the gastroenterologist. Clin Gastroenterol Hepatol 2014; 12: 187-195

[24] Garcia DA, Regan S, Henault LE et al. Risk of thromboembolism with short-term interruption of warfarin therapy. Arch Intern Med 2008; 168: 63-69

[25] Kato M, Uedo N, Hokimoto S et al. Guidelines for Gastroenterological Endoscopy in Patients Undergoing Antithrombotic Treatment: 2017 Appendix on Anticoagulants Including Direct Oral Anticoagulants. Dig Endosc 2018; 30: 433-440

[26] Vanassche T, Hirsh J, Eikelboom JW et al. Organ-specific bleeding patterns of anticoagulant therapy: lessons from clinical trials. Thromb Haemost 2014; 112: 918-923 